\title{
Interorganizational Coordination and Awareness in a Nonprofit Ecosystem
}

\author{
Jennifer Stoll, W. Keith Edwards, Elizabeth D. Mynatt \\ GVU Center and School of Interactive Computing \\ Georgia Institute of Technology, Atlanta, Georgia 30332 \\ jstoll@gatech.edu,keith@cc.gatech.edu,mynatt@gatech.edu
}

\begin{abstract}
Nonprofit organizations working with high-risk vulnerable populations such as human trafficking victims often need to engage in a significant level of interorganizational collaboration. Given the importance for nonprofits to be able to work with many different organizations, and given the importance of awareness in initiating and facilitating such collaborations, we conducted a field study to explore existing practices around coordination and awareness across a specific ecosystem of nonprofit organizations. In this paper, we provide an in-depth reflection on interorganizational issues among a cross-section of nonprofits. We identify four aspects of the interorganizational context in which these nonprofits must operate, as well as challenges they may encounter. Our goal is to illuminate first steps towards finding appropriate technological solutions for supporting coordination and awareness between these organizations so they can be more effective in accomplishing their mission.
\end{abstract}

\section{Author Keywords}

Interorganizational coordination, awareness, nonprofit organizations, networks, collective action.

\section{ACM Classification Keywords}

K.4.2 Social Issues: Miscellaneous.

\section{INTRODUCTION}

Nonprofit organizations that serve high-risk vulnerable populations (HRVPs) comprise some of the more challenging subsectors within the nonprofit sector. These populations, which include the homeless, victims of human trafficking, and others, are often illiterate, unable to access what mainstream users come to view as basic technologies such as phones or computers, and frequently require a level of services and care that demands complex and orchestrated

Permission to make digital or hard copies of all or part of this work for personal or classroom use is granted without fee provided that copies are not made or distributed for profit or commercial advantage and that copies bear this notice and the full citation on the first page. To copy otherwise, or republish, to post on servers or to redistribute to lists, requires prior specific permission and/or a fee.

CSCW 2010, February 6-10, 2010, Savannah, Georgia, USA.

Copyright 2010 ACM 978-1-60558-795-0/10/02...\$10.00. resources from a wide-range of organizations over a period of months or even years. Since no single organization can provide the diverse set of resources and services necessary to serve HRVPs, public sector and nonprofit organizations try to cope through collaborative interorganizational efforts.

Research by Ugarte et al. [11] demonstrate the critical importance of such interorganizational collaboration needed by organizations to effectively accomplish their mission. In one case study, they enumerate 21 different organizations that had to be involved in the identification, intervention, and subsequent rescue of a 15-year old victim of sex trafficking [11]. These organizations ranged from government agencies such as the Mexican Judicial Federal Police, the Desarrollo Integral de la Familia to investigate the victim's family, the Mexican Consulate Minor Protection, the US attorney's office to help prosecute the traffickers, a group home in Georgia to provide shelter in case management, the FBI, the San Diego Sherriff's Department, and so forth. This list demonstrates the extent to which organizations working with HRVPs often must coordinate with other organizations: in fact, such interorganizational collaboration is a necessity for many nonprofits to accomplish their mission.

However, such interorganizational collaboration also means that they must grapple with the significant complexity added by having to cooperate across international borders, and different state and city jurisdictions. Particular to the case of human trafficking, the mobility of many victims means that they cross jurisdictional lines, requiring coordination among both nonprofits and the legal establishment in several locales in order to provide service and prosecute traffickers. The diffuse nature of the human trafficking problem escalates the complexity of the coordination required and can lead to inefficient interorganizational cooperation where there is confusion, unnecessary redundancy, and gaps in services. According to the U.S. State Department, human trafficking is a significant issue globally, as well as in major cities across the U.S. (e.g., New York City, San Francisco, Atlanta, Los Angeles, New Orleans, Seattle, Philadelphia, Chicago, and Dallas among others); there are potentially 27 million victims of trafficking worldwide [38]. Those who engage in human trafficking tend to prey on the vulnerable such as young children, women who were orphans and the 
impoverished. For example, in one Southeast Asian country, a child can be purchased from a destitute family for a few dollars to be a sex-slave at a brothel [2]. The complexity in coordinating to address such a wide-spread problem is further increased by the specialization or "siloing" present in this (and many other) nonprofit subsectors: specific nonprofits may focus on narrow slices of the overall service picture, such as victim counseling, immigration assistance, job placement, child care, and so forth $[11,17]$.

While settings in which complex coordination work takes place have often been a topic of CSCW-related research (e.g., [1, 15, 24, 3, 41]), few studies have focused specifically on the challenges of coordination in the interorganizational context, specifically when this coordination may involve radically different types of organizations, such as nonprofits, policy makers, and legal authorities. To better understand the unique challenges and opportunities in this context, we began our work with nonprofits in early 2008, focusing specifically on a HRVP subsector known to involve a range of different stakeholders that must collaborate out of necessity: organizations dedicated to mitigation of human trafficking, and support for victims of trafficking. Our goals were both to characterize current inter-organizational coordination practices and challenges, and identify opportunities for technology to support crossorganizational information sharing.

During that time, we were told by many of our study participants of the challenges faced by their organizations in not only coordinating action but also in even knowing which relevant other organization might exist in the first place. Our participants described a "felt need" in the antitrafficking community for a means to help members of the public and other organizations "find each other." In other words, the challenges faced by these organizations included not just problems in coordinated action, but also what might be termed interorganizational awareness-knowing what other organizations might be out there that could help with a particular case. This awareness of other organizations plays a critical role in the capability of nonprofits to initiate and facilitate the collaborations needed in their work [11, 37].

To investigate the coordination and awareness challenges among nonprofits, we conducted a field study over a period of five weeks of 17 different organizations, including nonprofits, governmental agencies, policy makers, and police departments. This paper presents the results of that fieldwork. We organize the findings along the following four themes: 1) pockets of awareness between nonprofit networks, 2) conflict in interorganizational collaboration modes, 3) power asymmetries between donors and organizations, and 4) (in)congruity between nonprofits and for-profit organizations.

Our research contributions are two-fold. First, we provide insight into a problem domain that has not been widely studied in CSCW, yet which has a high need for collaboration and coordination. Second, we explore how specific characteristics of this problem domain-including structural, factors, technological factors, and organizational factors - pose challenges for simply applying technological solutions that may work in the for-profit world. These insights illuminate opportunities for addressing the unique set of collaboration challenges and opportunities that exist in this domain.

\section{RELATED WORK}

Intra-organizational, rather than inter-organizational, coordination and awareness has been studied extensively, particularly in the context of groupware system use [1, 14, 19, 23]. However for clarification, we reiterate here two key differences in our work from this existing research. The first is that in our work, we do not evaluate any system designed as a solution to address coordination and awareness problems. The second and more importantly, is that our study focused on coordination and awareness between nonprofit organizations rather than between persons within a corporate organization (such as individual knowledge experts as in systems like AnswerGarden, and Eureka [1, 3]). While our interorganizational focus differs from the work we mention, this prior research helps us to delineate the collaboration boundaries that needed to be considered in our study.

In the context of interorganizational literature, our research is informed by two sets of theories regarding coordination between organizations: the first is collective action research on networks of organizations [19,22], and the second is exchange and resource dependency theories [35]. With regard to collective action research, we draw upon Marwell and Oliver's designation of collective action as actions surrounding "mutual interests and the possibility of benefits from coordinated action" [22]. Based on literature on antitrafficking work, we see much opportunity for coordination between organizations (as explained by collective action theory) to be motivated by the mutual interest of mitigating human trafficking as well as benefits from coordinated action such as joint funding pursuits.

Although much of the literature [14, 27] focuses on overcoming obstacles to collective action within existing ties within an interorganizational network, we seek to contribute to this work with an in-depth examination of a context where interorganizational ties may not yet exist and the capability of developing such ties is hindered by external factors and challenges such as lack of awareness. Our intent is to provide a better understanding of the prior conditions needed to help organizations form effective network ties in pursuing collective action.

With regard to exchange and dependency theories of coordination between organizations, we understand through such theories that there are drivers for collaboration that act as catalysts for establishing ties between organizations. Two drivers identified in the literature that are particularly 
relevant to our work are task interdependency [27] and resource dependence [35]. Although we found evidence of these two drivers operating in the nonprofits we studied, our work complements this research by identifying what seems to be a goal-based driver for motivating coordination ties between organizations (this is discussed further in the second theme of the Findings section).

\section{STUDY DESIGN AND METHODOLOGY}

In our exploration of interorganizational coordination and awareness, we sought to address the following research questions: What technologies are organizations currently using to support coordination and awareness with other organizations? What are the challenges in doing so? How is such coordination and awareness information exchanged? What are the factors preventing the production and use of a directory of organizations?

Our fieldwork for this study consisted of both nonparticipant observations and semi-structured interviews. This study was conducted in two major U.S. cities, one located on the West Coast, which we refer to here as Westville and one near the Eastern seaboard, which we refer to here as Eastville. We selected these sites because both cities 1) are listed by the Federal Bureau of Investigation as top destination cities for the commercial sexual exploitation of children, and thus face major issues with human trafficking, 2) have a high-level of philanthropic activity focused on trafficking, meaning that there are well-developed ecosystems of nonprofits at each location, and 3) are regarded as being on the forefront of addressing the human trafficking problem as demonstrated by grants awarded by the Department of Justice to foster innovative coalitions to address the trafficking problem.

We chose to perform this study across two cities to allow us to sample across a wider range of coordination practices, and to help neutralize any particular local idiosyncrasies related to the cities themselves. While both Eastville and Westville are major metropolitan areas, they embody significant differences in both size and funding levels. These two cities are also situated in states that differ radically in terms of nonprofit activity; the number of nonprofits in Westville's state, for example, is almost double that of Eastville's state; likewise, the volume of revenue for nonprofits of the county for Westville is double that of the county of which Eastville is a part [29, 30].

\section{Participants}

We interviewed a total of 22 participants, representing 17 different organizations. All of our participants had a significant level of decision-making capacity in being able to form collaborations or alliances on behalf of the organization. The majority of the participants were from victim service provider organizations but also included two lawyers, one lobbyist, a police sergeant, a policy advisor to the mayor's office in Eastville, and one technology vendor. An equal number of participants were selected from both
Eastville and Westville. The smallest organization had three staff members while the largest organization had thirtynine. All nonprofits (with the exception of one) relied heavily on volunteers to fulfill their organizational mission. We specifically chose to interview those with a decisionmaking capability in forming alliances with other organizations because we felt these participants would be most informed regarding the coordination and awareness needs of their organization.

(To clarify, we note here that we specifically did not examine relationships between the organizations that we interviewed for a couple of reasons. First we felt that ties between those organizations would not necessarily indicate the complete network that we could reliably examine. Second, our focus for this study was on coordination and awareness that must occur prior to organizations forming a stable interorganizational network infrastructure that we could analyze as in the work of $[26,12,40]$.)

\section{Data Collection}

In order to prepare questions for the semi-structured interviews, we conducted a series of non-participant observations of three meetings. Two of the observed meetings involved interorganizational collaboration, in which $10+$ organizations gathered to coordinate, share information, and plan future directions for their organizations. The third meeting observation involved a single organization, and our observations here focused on collaboration among individuals within this organization in order to gain a better sense of the internal coordination and technology challenges faced by nonprofits in this space.

We devised our interview guide by focusing particularly on the following themes which emerged from our meeting observation data: 1) types of information sharing and collaboration activities with other organizations; 2) personal information management; 3) organizational information management; 4) technology tools used by the organization to facilitate coordination; and 5) challenges in accessing and maintaining awareness other organizations. We also collected organizational demographic information, such as numbers of employees and volunteers as well as the roles of individuals and the organization in the community.

We conducted the observations and interviews over the course of five weeks. The meeting observations used for designing the semi-structured interview totaled 3.5 hours. Interviews with each of the participants averaged 1.25 hours in duration for a total of 30 hours. For the data analysis and interpretation of the field notes, we employed a general inductive approach, guided by the work of Bryman $\&$ Burgess [4]. We were not guided by a specific hypothesis to test; rather we sought to examine the data for emerging themes relevant to interorganizational awareness and coordination in a specific nonprofit subsector. To derive the four themes presented in this paper, the interview transcripts were coded and analyzed both individually and then horizontally (across transcripts) for categories. We 
then grouped these categories into broader themes. In our study, we transitioned from conducting interviews to data analysis when we began detecting recurring patterns and themes arising from later interviews that had been identified in earlier ones. As part of our analysis, we briefly reviewed and corroborated our findings with select participants in our study who had significant years of experience in the work against human trafficking.

\section{FINDINGS AND ANALYSIS}

Below we present a discussion of the four themes that emerged in our exploration of interorganizational collaboration and awareness among the nonprofits studied.

\section{Operating in Pockets of Existence Awareness}

We know from interorganizational literature that existence awareness as defined by Thellufsen et al. is simply an internal "awareness of other organizations in the interorganizational network"; it is considered a necessary precondition for the other types of more complex awareness between organizations such as: collaboration, cooperation, coordination, implementation and evolution [37]. As noted in the introduction, many nonprofits are driven to coordinate with each other out of necessity - factors such as limited resources in any one organization, specialization of services offered, and the distributed geographical nature of problems such as human trafficking mean that addressing specific cases requires coordinated action and information sharing among a cohort of disparate organizations.

However, such coordinated action is impossible if a given organization is not aware of even the existence of others that might be potential collaborators. Our data suggest that the "existence awareness" problem faced by the nonprofits in our study was more subtle than a simple problem of being utterly unaware of other relevant organizations. On the contrary, our participants regularly noted that they were well aware of other organizations on which they could rely on a daily basis. However, participants noted the limits to their organizational awareness, particularly the failure of awareness to extend beyond the small handful of organizations that were already within their particular interorganizational network. This lack of awareness was problematic enough that P8's organization had decided to make as part of its mission the task of connecting organizations with others where possible to increase awareness among the anti-trafficking community.

Typically, the limits of existence awareness became exposed when an organization that provided a particular service within their network became unavailable (due to shutting down operations from lack of funds or the departure of key individuals), or when a given case required a service unavailable in their current interorganizational network. Participants P3 and P4 explained how their organization attempted to address their awareness issues by creating a compilation of other organizations called the "Resource Binder." Unfortunately, the binder was often underutilized because it was unclear how reliable or current the information was in the binder. A high turnover in the staff and volunteer rate often contributed to incomplete knowledge transfer among the nonprofit workers, leading to the obsoleteness of attempts to address organizational awareness issues such as the binder.

Participants noted that these problems were further exacerbated when their knowledge about even those organizations that were in their networks became outdated or unreliable, for example, when a key contact in a given partner organization departed. A common theme among the participants in our study was the essential importance of personal relationships with key individuals in partner organizations; especially given the nature of the at-risk populations served by these organizations, a history of trust with individuals at partner nonprofits, in some cases built up over a period of several years, was seen as essential in well-functioning networks. When a trusted peer left, existence awareness even for organizations within the network was often severely impacted. These breakdowns meant that organizations were effectively stuck within a pocket of awareness bounded by the limits of their particular interorganizational network, without the means to easily extend beyond it despite the regular need to do so.

Although their immediate interorganizational network was sufficiently large to accomplish some of their mission as nonprofits rescuing victims of human trafficking, participants noted that these networks proved to be inadequate, especially in cases where networks lacked redundancy (such as when redundant services were needed because an organization previously providing the service was shut down), or did not have the internal ability to provide some service (meaning that organizations were unable to provide some needed service without forming a connection external to the network). In the end, what the organizations we studied were looking for was a means to move beyond the pocket of interorganizational awareness and to expand their knowledge of other organizations actively working in the anti-trafficking domain. Unfortunately, they seemed to have no easy means of moving out of their pocket of limited existence awareness. This frustration was expressed by a number of participants such as P19 and 13 .

P 19: We're so not connected; it's hard to know what others [organizations] are doing. The traffickers seem way more organized that we are. It's really sad.

P13: More streamlining of organizations is needed. Groups are doing redundant work in areas we don't need and there are gaps in services needed.

The necessity of moving beyond limited pockets of awareness is driven by the complexity and scale of organizations involved in trafficking mitigation, as as in Ugarte et al.'s work enumerating 21 different organizations involved in the case of one individual [11]. Responses from our participants indicated that their experiences in 
coordinating with a large number of organizations were consistent with Ugarte et al.'s findings. A further complicating factor noted by our participants was that coordination was highly contextually dependent; in other words, the specific network of services (and organizations providing those services) needed for a given case could vary on a case-by-case basis, with some cases requiring interactions with remote legal authorities, others requiring specialized immigration assistance, and so forth. The fact that organizations existed in limited pockets of awareness made these complicating factors much more visible and apparent to our participants, and much more deleterious to the services they could offer their clients.

Participants in our study reported a continual, yet imperfect process of relying on a variety of information resources, such as personalized databases, search tools for online information, publicly available data, and so on in attempts to address their existence awareness challenges. Participants were creative and resourceful in seeking out other organizations, with many discussing a variety of systems they had tried. These ranged from specialized software systems such as CASESYS (for case management) and GiftNet (for mailing list management), to home-grown Excel spreadsheets, social networking applications such as Facebook, or simple paper and pen. Participants often reported these systems to be insufficient to their needs. P3, for example, resorted to using newspaper stories to try to find others in the community focusing on anti-trafficking:

P3: We search through the local newspapers in the community to find out about meetings.

Specialized software systems were also generally useful for other aspects of non-profits work; despite attempts at repurposing them toward organizational awareness goals, they were often inappropriate:

P20: We use GiftNet for our mailing list. But we don't use it to help us coordinate with other organizations. It wouldn't help us know who to contact for things that we need to help our clients.

Despite the differences in their various attempts, a common message was that their current methods-whether online, paper-based, or centered around existing interpersonal social networks - were insufficient to address the dynamic and context dependent nature of the existence awareness information needed by these organizations. Indeed, despite the similar missions of many of these organizations, and the need for coordinated action, the technological and organizational structures available to them were unable to adequately sustain and grow effective interorganizational existence awareness for more complex collaborations between networks.

\section{Conflict in Collaboration Modes}

From the interview data, indications of two different modes of collaboration emerged from description of coordination challenges facing participants' organizations. By collaboration mode, we refer to a goal-orientation that organizations seemed to adopt, which drove decisions to coordinate with other organizations. Some of those we interviewed made decisions to work with others primarily depending on the needs of their clients (former or potential trafficking victims). For example, according to P6 what motivated the initial contact with other organizations and the nature of the collaboration was driven by whether or not such actions benefited the victim; other priorities such as organizational growth, sustainability or increasing their competitive edge did not appear to be drivers. In our analysis, we labeled this as the victim-centric mode of collaboration. This mode was primarily characteristic of nonprofit organizations commonly identified by participants as "service providers;" that is, organizations providing services such as advocacy, counseling, drug rehabilitation, housing, job training, etc. However, nonprofits not working directly with clients exhibited the victim-centric collaboration mode as well. For example, one organization whose primary activities are raising awareness and directing resources made collaboration decisions mainly based on whether or not such affiliations would be beneficial to helping trafficking victims.

The other mode of collaboration that emerged from the data is what we labeled the process-centric mode. Organizations that are process-centric make decisions to work with other organizations based on existing processes such as those defined by law or by business best practices. Examples of organizations likely following this mode include law enforcement, policy makers, government contractors, and for-profit organizations providing services to clients as a business. How the collaboration is initiated and the nature of the coordination occurring between others and an organization following the process-centric mode is often defined a priori. That is, the protocols for engagement with other organizations are pre-defined by the law such as in the Juvenile Justice Code and coordination actions that do not fit within the Code or business process are not executed by the organization. This is in contrast to the victim-centric mode where coordination decisions are often made in realtime and based on protocols that more situational, negotiated, and implicit (that is not explicitly written into laws, for example).

Differing modes of collaboration became a significant obstacle for organizations being able to effectively coordinate: differences in priorities, procedures, and regulatory restrictions made the interfaces between organizations problematic. Some of our participants provided examples of how the progress made in rescuing trafficking victims were oftentimes undone or completely reversed by stakeholders adhering to the process-centric mode of operating. Additionally, participants such as P22 (from a nonprofit organization) and P24 (from a law enforcement unit) expressed frustration at the conflicting modes of operating. P22 gave examples of how with the current state of the law, victims are criminalized before perpetrators who enslaved the victim. Although those in the 
justice department were aware of the irony of following the judicial process, they were bound in their actions by "the process." P24 gave examples of how law enforcement members often had to avoid giving "common sense" help to victims, such as taking them to the nearest shelter for children due to jurisdictional issues dictated by "the process." Even if law enforcement organizations were aware of specific individuals or organizations who would be most able to provide the necessary assistance to a victim in a given situation, they would often prioritize the regulations and procedures of their organizations over victim needs, when those conflicted.

\section{Power Asymmetry and "Saving Face"}

Another theme that emerged from our data is that of power asymmetries and "saving face" among the organizations we interviewed. Paradoxically, there was an unwillingness among organizations to devote resources specifically to organizational or technological infrastructure intended to support coordination and interorganizational awareness. Such efforts were seen as "strategic" rather than oriented toward the more "tactical" mission of the organizations, to serve their clients. Although they realized such a need existed and that it was critical for greatly enhancing their ability to work more strategically with other organizations, as one participant stated:

\section{P8: Nobody wants to pay for doing the strategic!}

According to P8, organizations want to be perceived as accomplishing a mission rather than devoting resources to the strategic maintenance of broader interorganizational structures. Described as an effort to "save face," organizations actively worked to manage their perceived identities as solely focused on the needs of victims.

This active identity management was also driven by the fierce competition for resources in this ecosystem. Participants attested to having to compete with other organizations in the same subsector for resources such as funding and volunteers. One participant provided an example of such competitiveness where attempts were made to work with two other organizations to produce a campaign for raising awareness about Westville's sex trafficking problem. The campaign was fully developed in terms of message and creation of materials for the campaign; unfortunately it was never executed because one organization, in the end, did not wish to devote funds to a project where it would not be the sole nonprofit to receive credit for undertaking the campaign. In other words, a joint campaign to raise awareness about the plight of trafficking victims was sabotaged because it would bring insufficient recognition to one of the participating nonprofits.

The competition for funding focused the efforts of the organizations we studied on what were considered "fundable" aspects of their mission, whereas and away from more strategic efforts that were not considered fundable. The power asymmetry between the "funder" and "fundee" causing a lack of strategic focus is inline with Pfeffer and Salancik's [35] findings, as well as Galaskiewicz [14] where the amount of money that nonprofit organizations received from giving entities, such as corporations, was a function of the organization's perceived reputation in accomplishing their mission. The tension between cooperating to help victims of trafficking, yet needing to yield the requirements of the organization's donors perhaps indicates a reason why resources for resolving coordination and awareness problems among the organizations we studied may not have been allocated. The issue may be more complex than simply a scarcity of technology resources or access to technological know-how, but rather the power asymmetry caused by donors emphasizing a purely mission-oriented use of funds, and the resulting tensions raised by the competition for these funds.

\section{Challenges for Nonprofit Organizations}

A corollary theme that emerged to the theme of power asymmetries and "saving face" is the seemingly dual nature of nonprofit organizations where their operational behavior was in contrast with their stated mission. According to our participants, in order for nonprofit organizations to be deemed successful, they felt the need to behave with the efficiency of for-profit organizations while at the same time accomplishing a mission that was far removed from that of the typical for-profit enterprise. Work by Galaskiewicz [14] shows that this pressure to operationalize as a for-profit can come from donors who impose isomorphisms in ways such that environmental demands force nonprofits into mimicking for-profit organizations.

Despite the uptake of various for-profit motives, such as efficiency, and certain aspects of for-profit technologies, others have commented on the significant differences that exist between the for-profit enterprise and non-profit organization (see, for example, Merkel et al.'s work [25]). Our study points to a number of specific aspects of the inter-organizational coordination and awareness challenges that may highlight needs that are more characteristic of the non-profit setting. Below, we discuss four specific challenges that emerged from our data.

\section{A. Primacy of Individuals Over Organizational Boundaries} One significant finding that emerged in the organizations we studied is what we call the primacy of individuals over organizational boundaries. Given the specialization and competition among the anti-trafficking nonprofits in our study, and especially the strong emphasis on managing a unique and carefully cultivated "organizational identity," we had expected to observe strict boundaries between potentially competing organizations. To our surprise, however, participants reported this strict separation as of minimal priority. This finding is in agreement with Merkel et al. who state: "the sociotechnical gap-the gap between social requirements and what we can support technically-is by default a larger one in nonprofit community organizations versus for-profit, workplace 
environments because the underlying organizational structure is often invisible in the former" [25]. Our finding as well as Merkel et al.'s both indicate the possible emergence of "boundary-less organizations" as identified by Nohria and Berkeley [31]. Participants noted the primacy of individuals over organizations for coordination purposes; for instance, as P4 explained:

P4: [paraphrased] Who you know in an organization is more important than just knowing about the organization. If a person leaves an organization, we keep in touch with that person and not the organization.

The primacy of personal relationships often facilitated information flow among organizations. Trust relationships and collaboration decisions were made primarily on an individual basis although familiarity of the organization may have been a starting point. However, in most examples provided by participants, most of the coordination activity began with an individual's personal network of contacts.

P20: Contact information is connected and maintained on an individual basis. Everyone has their own list of contacts they use [for coordinating with other organizations].

While the importance of the "salesman's Rolodex" of individual connections is a long-standing meme in the forprofit world, such individual, interpersonal ties appear to play a key role in the nonprofit organizations in our study. These ties served as a way for information to crossover organizational boundaries more easily and encourage network formation, even in cases where the organizations may have otherwise been in a competitive relationship. One consequence of placing primacy on the individual over the organization is that the possibility of increasing coordination and awareness of other organizations was dependent on the quality of contacts of the individual rather than the quality of contacts based on the organization as a whole. Because an individual is followed rather than the organization, if an individual ceased work in this area, the opportunity to establish and utilize the contacts of others in the organization was often overlooked as well.

(We note here that the emphasis on the individual by the organizations we studied should not be confused with Useem's "interlocking directors" as discussed in [39] where a power elite holding multiple simultaneous directorships wield enormous political power within the larger community. Although we interviewed some participants who had formal designations as the director of their organizations, they were not necessarily members of some power elite as those on a board of directors but those directing the nonprofit at an operational level rather than at the strategic mission-crafting level.)

\section{B. High Turnover in Organizational Population}

Stakeholders in our study-like those reported in other studies of nonprofits [17] - rely on volunteer labor in order to accomplish their mission. This reliance on volunteer labor, in turn, created challenges for interorganizational coordination and awareness. Our participants reported a number of challenges for their organizations, particularly in planning for organizational longevity. Many organizations fail to plan for sustainability, i.e. being operational in the coming years; consequently, there is a high failure rate of organizations. This, in turn, was reported as contributing to the challenge of forming stable collaborative relationships with individuals in other organizations, even though such relationships were reported as necessary for "getting the job done." This situation can lead to frustration as expressed by one participant:

P8: I wish these organizations would stay in place and remain once I find out about them so I could make referrals.

This instability exists among the individuals with whom others rely on as well. For example:

P15: When [an elected official] leaves office, everyone associated with them leaves as well. And we have to make a whole new set of contacts.

Such instability in terms of both organizations and individuals compounds the difficulties of moving beyond simple existence awareness to a more long-term coordination or collaboration; this instability is especially problematic in light of the fact that, coordination among organizations could span over several years in cases such as the treatment and full recovery of trafficking victims, as noted by [42].

\section{Extreme Asymmetries in ICT Access}

Another critical difference between nonprofits and forprofits is a lack of symmetric information and communications technology (ICT) access. Participants in our study reported the difficulties inherent in interorganization coordination in the presence of an often extreme asymmetry in the availability of technology resources among the various stakeholders. For example, some service providers were technologically sophisticated and well-equipped, utilizing laptops, iPhones, chat servers and document management systems; others, however, had access only to mobile phones available depending on whether the service fee was paid in a timely fashion.

P12: There are no guarantees that the person you need to connect with will have an office or computer or even a phone.

Participants reported that the resource constraints posed by lack of funding acted as a de-motivating factor for coordination, as they were reluctant to divert scarce resources away from individual service and toward technology for coordination with other organizations. This led many organizations to rely upon a ramshackle assemblage of heterogeneous, and often personally owned, ICTs for their coordination work. P3's comments were typical of this style of technology use:

P3: We use our own laptops and cell phones to get our work done. Not everyone has a computer in the organization. And it's easier to use our own equipment. 
This style of technological appropriation is in stark contrast to the for-profit environment, in which each employee often has access to a homogeneous range of ICTs-laptops, Blackberries, email servers-provided for them (and managed) by the corporation. The resulting asymmetries in access to ICTs in nonprofits, whether because of differences in funding constraints, or because of differences in local expertise in deploying and managing ICTs, can increase the overhead required in maintaining intra- and inter-organizational communications. For example, individuals working in these organizations not only must keep track of contact information for colleagues, whether inside or outside their own organizations, but must also keep track of the best way to reach colleagues, whether in person at specific locations, by phone, email, or other via other individuals.

P5: I spend a lot of time trying to just send messages to people because it has to be sent in so many ways. I wish I could just send write one message and a system would just be able to figure out how the message needed to be sent, whether it's by phone or email or some other means.

Thus, for the organizations in our study, such extreme asymmetry creates additional challenges for them to promote coordination and collaboration with peers.

\section{Fighting a Crisis Under "Normal Conditions"}

The final difference we identified in the data was the reality of these organizations we interviewed as having to fight human trafficking as a humanitarian crisis that is ongoing under what participants described as "normal conditions." Unlike other crises such as earthquakes, fires, tsunamis and hurricanes, the human trafficking problem can be characterized as pandemic and not largely bound to a specific geographic location where the crisis is caused by a bounded event in terms of time of occurrence and anticipated resolution; it is also systemic, where the mechanisms allowing exploitation are often entrenched in political, economic, and social systems [11, 38]. Consequently, the organizations we interviewed seemed to struggle with many tensions that are perhaps more extreme than in the for-profit context e.g., having to conduct covert actions in rescuing a victim while maintaining the facade of normal operations, or having to go to great lengths to establish a trust relationship before more in-depth coordination efforts can progress. To illustrate using the latter as an example, our data illustrate how trust work often took the form of face-to-face meetings or an extensive phone conversation to understand who the individual was connected to, their motivations for involvement in antitrafficking work, and whether or not they would be beneficial actor on behalf of the victim and in what capacity.

P7: When I'm on a call with someone I don't know, I take lots of notes about whether the person is trustworthy and how they talk about the victim. That's very telling; whether they really care.
This finding echoes previous studies in other "high risk" contexts, for example, in the work of gang violence reduction or international truth and reconciliation efforts, in which a misstep can lead to the death of clients or service providers or others attempting to provide assistance to victims.

P13: We have to be careful of who we trust otherwise the victim as well as the service provider could be in danger.

This trust work, however, is not just centered around establishing a trust relationship between the organization and the individual; it also extends to trust relationships between organizations themselves. Participants noted that an organization that refers an individual to another organization for service must have a prior, and wellestablished, trust relationship with that organization, otherwise they may be putting their clients at risk.

Unfortunately, although among for-profit organizations many laws, policies and established protocols exist for ensuring that business relationships remain ethical and reliable through a system of taxation, penalties and regulations, nonprofits organizations (depending on how they are funded, whether publicly or privately) are often not accountable under such structures. As a result, nonprofits do not receive the benefits of state vetting of their organizational peers; thus our participants reported devoting a significant amount of time to fight against the established system to accomplish their mission.

\section{DISCUSSION AND CONCLUSION}

To summarize, we investigated interorganizational coordination and awareness issues among a group of nonprofit organizations engaged in anti-trafficking work. We were motivated by the fact that anti-trafficking work is necessarily highly collaborative and also by the specific challenges to collaboration that exist in this environment, which prevent coordinated action and even basic existence awareness of other organizations.

Our work has illuminated a number of aspects of the collaborative context for one particular ecosystem-the network of nonprofits, governmental agencies, policy makers, and enforcement authorities involved in coordinated action against human trafficking. Despite the necessity of coordinated action within this ecosystem, brought about by specialization among agencies, the spanning of geographic boundaries, and other causes, a number of factors limit the efficacy of organizations working together. These factors are structural (hinging on factors in the ecosystem itself, such as inherent competitiveness due to funding pressures), technological (such as asymmetry in ICT access), organizational (reliance on volunteer workforce), and individual (hinging on personal motivations and trust relationships among individuals).

The four themes that emerged as part of the context point to particular nuances of the nonprofit context that should be 
considered in designing solutions to facilitate collaborations between organizations. The primacy of individuals over organizations indicates that a direct translation of an organization's contacts list of other organizations into something online may be insufficient for conveying adequate interorganizational awareness. A straightforward sharing of contact information loses aspects of the trust relationship that are essential in this subsector. Additionally, the high turnover in organizational population introduces a temporal element into the coordination dynamic, since the rapid decay in data "freshness" complicates interorganizational awareness. The dynamics of power asymmetry and "saving face" and having to fight a crisis under "normal conditions" indicate that simple lists posted in a publicly accessible way will likely be insufficient to convey the rich interorganizational awareness data that our participants must necessarily rely on to accomplish their mission.

Our data characterizing this ecosystem points to the need to facilitate interorganizational collaboration - particularly for nonprofit subsectors that must go beyond one-to-one collaborations with organizations. Further research is needed to identify the specific dimensions of coordination and awareness information that are useful for facilitating collaboration that spans the full range of interorganizational relationships [16]. Having examined collaboration and interorganizational awareness issues across a cross-section of nonprofits enabled us to identify a larger pattern of collaboration challenges than would have been possible by focusing on just one or two organizations.

The challenges our participants faced in interorganizational coordination and awareness may be indicative of an emergence of a nonprofit network. That is, since the organizations we studied must necessarily pursue a high degree of interorganizational interactions, one possible interpretation of the findings based on interorganizational theory is that the nonprofits we studied may be part of an emerging network organizational form. As described in [36], a network organizational form is composed of a collection of actors, such as independent nonprofits, "that pursue repeated, enduring exchange relations with one another and, at the same time, lack a legitimate organizational authority to arbitrate and resolve disputes that may arise during the exchange." What seems to drive the emergence of a network organizational form among the nonprofits we studied could be explained by task interdependence [27] and resource dependence [35]. Our finding regarding the differing collaboration modes potentially augments existing interorganizational theory regarding these drivers for the emergence of the network organizational form by identifying a goal-based driver. It is also possible that the challenges we identified such as operating in pockets of awareness would be indicative of any group of organizations in an emerging network state.

In interpreting our findings regarding interorganizational coordination and awareness challenges as being indicative of an emerging network organizational form, we believe that more research will be needed to understand the exact nature of these nonprofits as a network. The work by Denning and Hayes-Roth regarding Hastily Formed Networks and the levels of networks identified in [8,9] may provide some guidance in this regard. Often the interorganizational coordination and awareness needs of the nonprofits we studied were beyond that supported in the design of many systems primarily created to facilitate collaboration within an organization. We believe that this points to potential future work in understanding how coordination and awareness can be better supported beyond the individual to the interorganizational and inter-network contexts.

\section{ACKNOWLEDGEMENTS}

The authors wish to thank Hans Klein and John Walsh from the School of Public Policy at Georgia Tech for their insightful comments and generous guidance on this paper.

\section{REFERENCES}

1. Ackerman, M. S. and Malone, T. W. Answer Garden: a tool for growing organizational memory. In Proceedings of the ACM SIGOIS and IEEE CS TC-OA Conference on office information Systems (Cambridge, Massachusetts, United States, April 25 - 27, 1990). F. H. Lochovsky and R. B. Allen, Eds. ACM, New York, NY, 31-39 (1990).

2. Batstone, D. Not for Sale: the return of the global slave trade - and how we can fight it. HarperOne, 2007.

3. Bobrow, D. G.; Whalen, J. Community knowledge sharing in practice: the Eureka story. Reflections, the SOL Journal. Winter; 4 (2): 47-59, (2002).

4. Bryman A., Burgess R.G. (eds). Analyzing qualitative data. London: Routledge (1994).

5. Burt E., Taylor J.A. "Information and Communication Technologies: Reshaping the Voluntary Sector?" Centre for the Study of Telematics and Governance, Glasgow Caledonian University (1998).

6. Burt E., Taylor J. "Advanced Networked Technologies in the U.K. Voluntary Sector". Voluntas: Int'l Journal of Voluntary and Nonprofit Organizations, 12:4, (2001).

7. Chisholm, D. Coordination Without Hierarchy: Informal Structures in Multiorganizational Systems. University of California Press, Berkeley, CA, (1989).

8. Denning, P. Hastily formed networks. Communications of the ACM, Vol. 49, No. 4, (2006).

9. Denning, $\mathrm{P}$ and Hayes-Roth, R. Decision making in very large networks. Communications of the ACM, Vol. 49, No. 11, (2006).

10. Donnelly et al. Building an Internet resource for a specialized online community. DOC'94, Banff, Alberta, Canada (1994). 
11. Farley, M. Chapter 12. Prostitution \& Trafficking in Nevada: Making the Connections. San Francisco, CA, Prostitution Research and Education (2007).

12. Frost, P., Moore, L., Louis, M. R., Lundberg, C., \& Martin, J. Organizational culture. Newbury Park, CA: Sage, (1985).

13. Fulk. Global network organizations: Emergence and future prospects. Human Relations (2001).

14. Galaskiewicz, J. Professional Networks and the Institutionalization of a Single Mind Set, American Sociological Review, Vol. 50, No. 5, pp. 639-658, American Sociological Association, (1985).

15. Greenberg, S. Peepholes: Low Cost Awareness of One's Community. ACM SIGCHI Conference on Human Factors in Computing System, Companion Proceedings, p. 206-207 (1998).

16. Hall, R.H., Clark, J.P., Giordan, P.C., Johnson, P.V., Roekel, M.V. "Patterns of Interorganizational Relationships". Administrative Science Quarterly 22 (1977) 457-474.

17. Hutchinson R., Quartaro E. "High-Risk Vulnerable Populations and Volunteers: A Model of Education and Service Collaboration". Journal of Community Health Nursing, 12(2), 111-119 (1995).

18. Klein, H., Kleinman, D. The Social Construction of Technology: Structural Considerations. Science (2002).

19. Knoke, D. Incentives in collective action organizations. American Sociological Review, Vol. 53, pp. 311-329, (1988)

20. Kraut et al. Informal communication in organizations: Form, function, and technology. Groupware and Computer-Supported Cooperative Work (1993).

21.Le Dantec, C. A., Edwards, W.K. The view from the trenches: Organization, Power, and Technology at Two Nonprofit Homeless Outreach Centers.” CSCW (2008).

22. Marwell, G., Oliver, P. E., \& Prahl, R. Social networks and collective action: A theory of the critical mass. III. , 94(3), 502-534, (1988).

23. Mathieson. Factors influencing intentions to maintain web content in voluntary organizations. (2006)

24. McEwan, G., Greenberg, S. Supporting social worlds with the community bar. GROUP'05, Sanibel Island, FL (2005).

25. Merkel C., Farooq U., Xiao L., Ganoe C., Rosson M.B., Carroll J.M. "Managing technology use and learning in nonprofit community organizations: methodological challenges and opportunities". CHIMIT, New York (2007).

26. Miles, R. E., \& Snow, C.C. Organizations: New concepts for new forms. California Management Review, 28, 62-73, (1986).
27. Monge, P., Contractor, N. Emergence of Communication Networks. Handbook of Organizational Communication, Thousand Oaks, CA: Sage, (1999).

28. Nagy, A. The Effect of Power on the Adoption of Interorganizational Information Systems: The Adoption Position Model. ECIS, (2004).

29. NCCS Registered Nonprofit Organizations by Major Purpose or Activity (NTEE Code) http://nccsdataweb.urban.org/NCCS/Public/index.php (2008)

30. NCCS Number of Nonprofit Organizations by State, 2006.http://nccsdataweb.urban.org/PubApps/profileDrill Down.php?rpt=US-STATE (2008).

31. Nohria, N., \& Berkley, J. D. The virtual organization: Bureaucracy, technology, and the implosion of control. In C. Hekscher \& A. Donnellon (Eds.), The postbureaucratic organization: New perspectives on organizational change (pp. 108-128). Thousand Oaks, CA: Sage, (1994).

32. Olson, M., Jr. The logic of collective action. Cambridge, MA: Harvard University Press, (1965).

33. Orlikowski W.J. The duality of technology: Rethinking the concept of technology in organizations. Organizations Science. Vol. 3:3, p398-427 (1992).

34. Pacilio et al. Evaluation of Episodic Communication Channels in Organizations. (2009) pp. 21

35. Pfeffer, J., and Salancik, G. The external control of organizations: A resource dependence perspective. New York: Harper \& Row, (1978).

36. Podolny J.M, Page K.L. "Network Forms of Organization". Annu. Rev. Sociol. 24:57-76, 1998.

37. Thellufsen, C. "Awareness as a foundation for developing effective spatial data infrastructures", Elsevier: Land Use Policy 26, p.254-261, (2009).

38. U.S. Department of State. Trafficking in Persons Report. www.state.gov/g/tip/rls/tiprpt/2008/105376.html (2008).

39. Useem, M. The inner circle: Large corporations and business politics in the U.S. and UK. New York: Oxford University Press, (1983).

40. Watzlavick, P., Beavin, J., \& Jackson, D. Pragmatics of human communication. New York: Norton, (1966).

41. Wellman B, Salaff J, Dimitrova D, Garton L, Gulia M, Haythornthwaite C. "Computer Networks as Social Networks: Collaborative Work, Telework, and Virtual Community”. Annu. Rev. Sociology, 22:213-38 (1996).

42. Williams, J.'Barriers to Services for Women Escaping Nevada Prostitution and Trafficking' in Farley, M. (ed): Prostitution and Trafficking in Nevada: Making the Connections, San Francisco, CA, Prostitution Research and Education, pp. 159-173, (2007). 